\title{
Normal flow-mediated vasodilatation of the brachial artery and carotid artery intima-media thickness in subclinical hypothyroidism
}

\author{
M.D. Cabral ${ }^{1}$, P.F.S. Teixeira ${ }^{1}$, N.A.O. Silva ${ }^{1}$, F.F.C. Morais ${ }^{1}$, D.V. Soares ${ }^{2}$, E. Salles ${ }^{3}$, \\ J.M. Henriques ${ }^{2}$, S.P. Leite ${ }^{4}$, C.A.B. Montenegro ${ }^{5}$ and M. Vaisman ${ }^{1}$ \\ ${ }^{1}$ Serviço de Endocrinologia, Hospital Universitário Clementino Fraga Filho, Departamento de Clínica \\ Médica, Faculdade de Medicina, Universidade Federal do Rio de Janeiro, Rio de Janeiro, RJ, Brasil \\ ${ }^{2}$ Serviço de Endocrinologia, Hospital Universitário Pedro Ernesto, Universidade Estadual do Rio de \\ Janeiro, Rio de Janeiro, RJ, Brasil \\ ${ }^{3}$ Divisão de Angiologia, Hospital Universitário Clementino Fraga Filho, Universidade Federal do Rio de \\ Janeiro, Rio de Janeiro, RJ, Brasil \\ ${ }^{4}$ Centro de Estudos e Pesquisas da Mulher, Rio de Janeiro, RJ, Brasil \\ 5 Ultra-Sonografia Botafogo, Rio de Janeiro, RJ, Brasil
}

Correspondence to: M.D. Cabral, Serviço de Endocrinologia, Hospital Universitário Clementino Fraga Filho, UFRJ, R. Guimarães Rosa, 143/204, 22793-090 Rio de Janeiro, RJ, Brasil

Fax: +55-21-3282-5071. E-mail: mdcabral@globo.com

Subclinical hypothyroidism (SHT) is a disease for which exact therapeutic approaches have not yet been established. Previous studies have suggested an association between SHT and coronary heart disease. Whether this association is related to SHTinduced changes in serum lipid levels or to endothelial dysfunction is unclear. The aim of this study was to determine endothelial function measured by the flow-mediated vasodilatation of the brachial artery and the carotid artery intima-media thickness (IMT) in a group of women with SHT compared with euthyroid subjects. Triglycerides, total cholesterol, HDL-C, LDL-C, apoprotein A (apo A), apo B, and lipoprotein(a) were also determined. Twenty-one patients with SHT (mean age: $42.4 \pm 10.8$ years and mean thyroid-stimulating hormone (TSH) levels: $8.2 \pm 2.7 \mu \mathrm{lU} / \mathrm{mL}$ ) and 21 euthyroid controls matched for body mass index, age and atherosclerotic risk factors (mean age: $44.2 \pm 8.5$ years and mean TSH levels: $1.4 \pm 0.6 \mu \mathrm{lU} / \mathrm{mL}$ ) participated in the study. Lipid parameters (except HDL-C and apo A, which were lower) and IMT values were higher in the common carotid and carotid bifurcation of SHT patients with positive serum thyroid peroxidase antibodies (TPO-Ab) $(0.62 \pm 0.2$ and $0.62 \pm 0.16 \mathrm{~mm}$ for the common carotid and carotid bifurcation, respectively) when compared with the negative TPO-Ab group ( $0.55 \pm 0.24$ and $0.58 \pm$ $0.13 \mathrm{~mm}$, for common carotid and carotid bifurcation, respectively). The difference was not statistically significant. We conclude that minimal thyroid dysfunction had no adverse effects on endothelial function in the population studied. Further investigation is warranted to assess whether subclinical hypothyroidism, with and without TPO-Ab-positive serology, has any effect on endothelial function.

Key words: Subclinical hypothyroidism; Lipid profile; Endothelial function; Carotid artery intima-media thickness

Research supported by Abbott Laboratories.

Received July 8, 2008. Accepted February 19, 2009 


\section{Introduction}

Subclinical hypothyroidism (SHT) is a disorder characterized by elevated serum thyroid-stimulating hormone (TSH) levels despite normal free-thyroid hormone values (1). The prevalence of SHT ranges from 5 to $10 \%$, and the condition affects 6 to $10 \%$ of women (approximately 15\% of women over 60 years of age) and 2.4 to $3 \%$ of the overall male population $(2,3)$. There is much controversy regarding the morbidity and clinical significance of SHT (4-7). An unanswered question is whether individuals with SHT have only biochemical abnormalities that need to be closely monitored or if further laboratory investigation and thyroid hormone replacement are warranted.

Although not a consistent finding, some studies have found that subjects with SHT have higher total (TC) and low-density lipoprotein cholesterol (LDL-C) levels than euthyroid subjects (8-10). The reports of lipid and lipoprotein changes in response to thyroid hormone replacement in the setting of mild thyroid dysfunction have been somewhat conflicting (10-12). Although a consensus is still lacking, the benefit of levothyroxine replacement in patients with SHT seems to be linked to the reduction of cardiovascular risk (by lowering both TC and LDL-C levels) with restoration of euthyroid status (12-14). Previous studies have suggested an association between SHT and coronary heart disease $(15,16)$. Whether this association is related to SHT-induced changes in serum lipid levels is unclear $(11,14)$. In a population-based survey, SHT emerged as a significant risk factor for aortic atherosclerosis and myocardial infarction in elderly women, independent of serum cholesterol levels (16). Therefore, further mechanisms should be investigated to clarify the role of SHT in cardiovascular disease. Data from several studies of coronary heart disease in subjects with SHT are conflicting and the current available evidence for a causal relationship between SHT and mortality is still uncertain (17, 18).

The endothelium plays a major role in the maintenance of vascular function and integrity through the production of vasodilator and vasoconstrictor substances $(19,20)$. Endothelial dysfunction, resulting in reduced availability of nitric oxide, has been identified as an early marker of atherosclerosis and can be used to predict coronary artery disease before the development of atherosclerotic changes (21). Recent studies have shown that hypothyroidism and SHT may have adverse effects on endothelial function independently of other well-known atherosclerotic risk factors (22-30).

The aim of the present study was to compare endothelial function measured by carotid artery intima-media thick- ness (IMT) and the flow-mediated vasodilatation (FMD) of the brachial artery between women with SHT and normal controls.

\section{Patients and Methods}

All subjects (cases and controls) were women recruited from the Outpatient Clinic of the Clementino Fraga Filho University Hospital (HUCFF), Federal University of Rio de Janeiro (UFRJ).

Twenty-one women with SHT and 21 euthyroid women were included. The inclusion criterion was at least two documented laboratory determinations of SHT, at least 6 weeks apart, defined by both elevated TSH $(>4.0 \mu \mathrm{lU} / \mathrm{mL})$ and normal free-thyroxine (FT4) levels. The patients had no previous history of thyroid disease. The maximum TSH value accepted for the SHT group was $12.0 \mu \mathrm{lU} / \mathrm{mL}$, while controls had $\mathrm{TSH}$ and serum anti-thyroid peroxidase antibodies (TPO-Ab) within the normal range and no history of thyroid disease. Patients were excluded from the study if they had a history of alcohol use, were suffering from concomitant non-thyroid illnesses (e.g., diabetes mellitus, arterial hypertension, liver, or renal diseases) or were using drugs that could interfere with thyroid, lipoprotein or endothelial function. Cases and controls were matched for body mass index (BMI), age and atherosclerotic risk factors. The study was approved by the UFRJ Institutional Ethics Committee and all subjects gave written informed consent to participate.

A general physical examination was performed including assessment of height (without shoes), weight and waist circumference (the minimum value between the iliac crest and the lateral costal margin). BMI was calculated as weight $(\mathrm{kg})$ divided by height squared $\left(\mathrm{m}^{2}\right)$. Systolic and diastolic blood pressures were measured from the right brachial artery of the subjects in a supine position after 10 min of rest using a pneumatic sphygmomanometer.

Venous blood samples were drawn between 8:00 and 9:00 am after an overnight fast of $12 \mathrm{~h}$. Serum was centrifuged and stored at $-80^{\circ} \mathrm{C}$ until assayed. Serum TSH, FT4 and TPO-Ab, TC, high-density lipoprotein cholesterol (HDLC), triglyceride (TG), apoprotein B (apo B), apo A, and lipoprotein(a) were determined in both groups.

Serum TSH, FT4 and TPO-Ab were measured by immunochemiluminescence (Immulite $2000^{\circledR}$; DPC, Diagnostic Products Corporation, USA). Reference ranges for $\mathrm{TSH}$ and FT4 were 0.4-4.0 $\mu \mathrm{lU} / \mathrm{mL}$ and 0.8-1.9 $\mathrm{ng} / \mathrm{dL}$, respectively. TPO-Ab levels of $>35 \mathrm{IU} / \mathrm{mL}$ were considered positive. The intra-assay coefficients of variation were 3.812.5, 4.4-7.5, and 4.3-5.6\% for TSH, FT4, and TPO-Ab, respectively. Inter-assay coefficients of variation were 4.6- 
12.5, 4.8-9.0, and 7.8-10.5\%. TC, TG (Vitros Chemistry Products assay, USA) and HDL-C (Boehringer Mannheim Systems, Germany) were determined enzymatically. LDL$C$ was calculated by the Friedewald equation: $L D L=(T C$ $\mathrm{HDL}$ ) - (TG/5). The reference ranges for TC, HDL-C, TG, and LDL-C were based on the III ATP of the National Cholesterol Education Program (NCEP) (31).

Lipoprotein(a) concentration was determined by an immunoradiometric assay (Diagnosis System International, Novatech, USA) and apo A and apo B were measured by rate nephelometric immunoassay (Beckman Coulter system, USA) and their reference ranges were lower than 30 , 90-200, and 30-100 mg/dL, respectively.

The subjects were investigated by high-resolution colorDoppler ultrasound imaging (Toshiba Nemium, Japan; 14$\mathrm{mH}$ linear probe) of the brachial artery in the dominant arm. The study was performed in a temperature-controlled room $\left(25^{\circ} \mathrm{C}\right)$ with subjects resting in the supine position. Study participants fasted for $8 \mathrm{~h}$ prior to the exam. Blood pressure and heart rate were recorded on the opposite arm every 3 min using an automatic sphygmomanometer. The subjects' dominant arm was comfortably immobilized in the extended position to allow consistent access to the brachial artery. Doppler ultrasound measurements were performed before and $60 \mathrm{~s}$ after reactive hyperemia. To avoid interobserver variability, all measurements were performed by the same examiner, who was blind to the subjects' clinical status. Brachial artery vasodilation in response to reactive hyperemia was determined by a previously validated technique $(32,33)$. The intraclass correlation coefficient of this technique has been reported previously by our laboratory and ranges from $R=0.7001$ to $R=0.8420(P<$
$0.05)(34,35)$. The scans were recorded on S-VHS videotape. The internal diameter of the brachial artery was assessed at the end of diastole, and arterial flow was measured using the pulse Doppler sample volume at an angle of $60^{\circ}$ or less in the center of the artery. For each subject, optimal brachial artery images were obtained approximately $5 \mathrm{~cm}$ above the antecubital fossa. Arm pressure was caused by inflating a pneumatic arm cuff up to $30 \mathrm{mmHg}$ higher than the subject's systolic arterial pressure for $5 \mathrm{~min}$. The cuff was then deflated, the arterial flow was immediately recorded, and the diameter was measured 60 to $90 \mathrm{~s}$ after deflation. Figure 1 illustrates a typical example of an image obtained. For both diameters, one measurement was made and the value was recorded. FMD was calculated according to the formula: FMD $=$ (posocclusion diameter - baseline diameter) $\times 100 /$ baseline diameter.

The IMT of the common carotid artery was calculated by the same examiner with high-resolution ultrasound imaging (Acuson Aspen Advanced model, $10 \mathrm{mH}$ linear probe, USA), as described (36). Briefly, the common carotid arteries were scanned at the level of the bifurcation on both the right and left sides. Subsequently, the IMT was measured in the far wall of the arteries at sites of most advanced atherosclerotic lesions, identified as diffuse and continuous projections with the greatest distance between the lumen-intimal interface and the media-adventitial interface but without atherosclerotic plaques (Figure 2). Localized lesions of $\geq 2.0 \mathrm{~mm}$ thickness were considered to be atherosclerotic plaques. Three measurements were made for each subject and the mean value was used for analysis. The scans were recorded on S-VHS videotape. Reproduc-
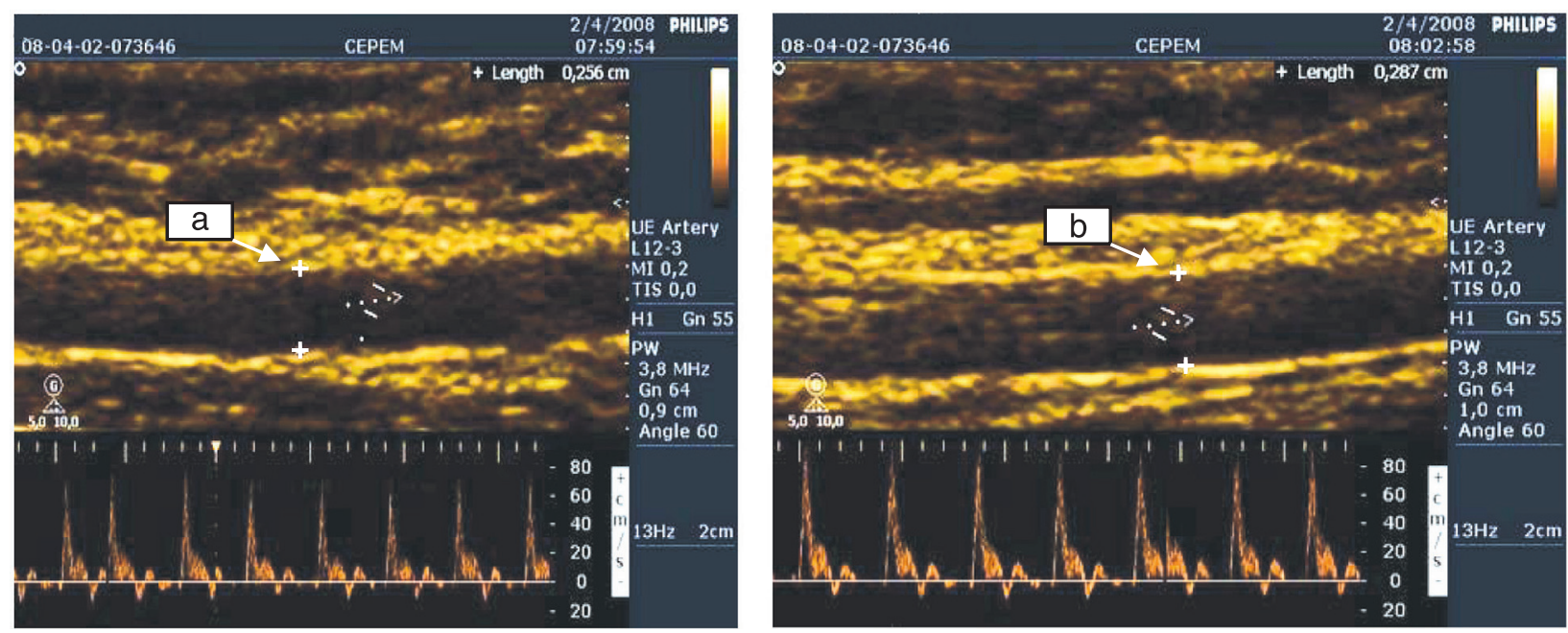

Figure 1. Brachial artery images obtained before arm pressure (a) and $60 \mathrm{~s}$ after deflation (b). 


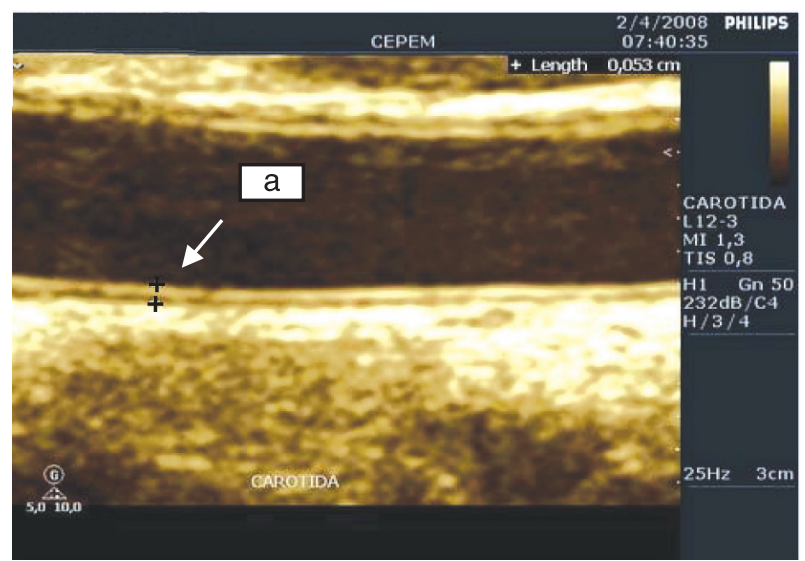

Figure 2. The greatest distance between the lumen-intima interface and the media-adventitia interface to calculate intima-media thickness of the carotid artery (a).

Table 1. Clinical and laboratory characteristics of the women with subclinical hypothyroidism.

\begin{tabular}{lcc}
\hline & EU $(\mathrm{N}=21)$ & SHT $(\mathrm{N}=21)$ \\
\hline Age (years) & $44.2 \pm 8.5$ & $42.4 \pm 10.8$ \\
Sedentarism $(\%)$ & $88.2 \%$ & $84.2 \%$ \\
Menopause $(\%)$ & $61.9 \%$ & $71.4 \%$ \\
Body mass index $\left(\mathrm{kg} / \mathrm{m}^{2}\right)$ & $24.6 \pm 3.7$ & $26.8 \pm 4.8$ \\
Waist circumference $(\mathrm{cm})$ & $84.2 \pm 13.6$ & $85.1 \pm 10.2$ \\
TSH $(\mu \mathrm{ll} / \mathrm{mL})$ & $1.2(0.7)$ & $8.3(4.3)^{*}$ \\
FT4 $(\mathrm{ng} / \mathrm{dL})$ & $1.2(0.3)$ & $1.0(0.1)^{*}$ \\
TG $(\mathrm{mg} / \mathrm{dL})$ & $110(61)$ & $98(47.5)$ \\
HDL-C $(\mathrm{mg} / \mathrm{dL})$ & $54.4 \pm 12.8$ & $55.6 \pm 10.8$ \\
TC $(\mathrm{mg} / \mathrm{dL})$ & $201.1 \pm 35.4$ & $227 \pm 49.4$ \\
LDL-C $(\mathrm{mg} / \mathrm{dL})$ & $112.9 \pm 33.3$ & $148.7 \pm 46.3^{*}$ \\
apo A $(\mathrm{mg} / \mathrm{dL})$ & $145.2 \pm 26.2$ & $156.9 \pm 29.1$ \\
apo B $(\mathrm{mg} / \mathrm{dL})$ & $104.4 \pm 28.3$ & $128.2 \pm 37.7^{*}$ \\
Lp(a) $(\mathrm{mg} / \mathrm{dL})$ & $15.3(28.6)$ & $18.6(71.05)$ \\
& &
\end{tabular}

Data are reported as means \pm SD or median (interquartile range). $\mathrm{EU}$ = euthyroid group; $\mathrm{SHT}$ = subclinical hypothyroid group; $\mathrm{TSH}=$ thyroid-stimulating hormone; FT4 = normal free thyroxine; TG = tryglicerides; HDL-C = high-density lipoprotein cholesterol; TC = total cholesterol; LDL-C = low-density lipoprotein cholesterol; apo $A=$ apoprotein $A$; apo B = apoprotein B; $L p(a)=$ lipoprotein(a). ${ }^{*} P$ $<0.05$ compared to EU group ( $t$-test and Mann-Whitney test).

Table 2. Brachial and carotid artery parameters.

\begin{tabular}{lcc}
\hline & EU $(\mathrm{N}=21)$ & SHT $(\mathrm{N}=21)$ \\
\hline Flow-mediated dilatation $(\%)$ & $16.1(8.8 \%)$ & $20.6(11.2 \%)$ \\
Intima-media thickness of CCA $(\mathrm{mm})$ & $0.6(0.1)$ & $0.6(0.1)$ \\
Intima-media thickness of bifurcation $(\mathrm{mm})$ & $0.6(0.2)$ & $0.6(0.1)$ \\
\hline
\end{tabular}

Data are reported as median (interquartile range). EU = euthyroid group; SHT = subclinical hypothyroid group; $\mathrm{CCA}=$ common carotid artery. There were no statistically significant differences between the EU and SHT groups (MannWhitney test) ibility of the IMT measurement was acceptable, as demonstrated by coefficients of variation of $7.7 \pm 4.3 \%$ (36).

\section{Statistical analysis}

Statistical analysis was performed using SPSS for Windows program, version 10.0. The mean values of the numerical variables were compared between groups by the Mann-Whitney test; if not normally distributed by the Kolmogorov-Smirnov Liliefors test. Parametric variables were compared by the $t$-test.

Data are reported as median values (interquartile range) of continuous non-parametric variables, as means $\pm S D$ values of parametric variables or frequencies of qualitative variables. Non-parametric variables are reported as median and range. A $P$ value of $<0.05$ was considered to be significant.

\section{Results}

The mean age of the $21 \mathrm{SHT}$ subjects was $42.4 \pm 10.8$ years and the mean age of the 21 subjects in the control group was $44.2 \pm 8.5$ years. The cause of SHT was spontaneous and 14 (70\%) SHT subjects had abnormal TPO-Ab levels. No significant difference was observed with respect to age, BMI, waist circumference, activity level, or menopausal status. There were no statistically significant differences in lipid parameters between cases and controls, except for LDL-C (148.7 \pm 46.3 vs $112.9 \pm$ $33.3 \mathrm{mg} / \mathrm{dL} ; \mathrm{P}=0.04)$ and apo $\mathrm{B}(128.2 \pm 37.7$ vs $104.4 \pm$ $28.3 \mathrm{mg} / \mathrm{dL} ; P=0.02$ ), which were significantly higher in the SHT group. The baseline clinical and laboratory characteristics of all participants are summarized in Table 1.

The median and range TSH values were $8.3(4.3) \mu \mathrm{IU} /$ $\mathrm{mL}$ for the SHT group and $1.2(0.7) \mu \mathrm{IU} / \mathrm{mL}$ for the euthyroid group. TSH was 4 to $8 \mu \mathrm{lU} / \mathrm{mL}$ in eight patients (38\%), and 8 to $12 \mu \mathrm{IU} / \mathrm{mL}$ in $13(62 \%)$.

No significant differences were observed with respect to FMD or IMT between the SHT and control groups (Table 2). When the SHT group was subdivided into low $(\geq 4$ but $>8 \mu \mathrm{IU} /$ $\mathrm{mL}$ ) or high ( $\geq 8$ but $<12 \mu \mathrm{lU} / \mathrm{mL}$ ) TSH levels, no differences were observed in metabolic, or vascular parameters. Lipid parameters, FMD, and IMT values were higher in the common carotid artery and carotid bifurcation of SHT patients with positive serum TPO-Ab $(0.62 \pm 0.2$ and $0.62 \pm 0.16 \mathrm{~mm}$, for common carotid artery and carotid bifurcation, respectively) compared to the negative TPO-Ab group $(0.55 \pm 0.24$ and $0.58 \pm 0.13 \mathrm{~mm}$, for common carotid and carotid bifurcation, respectively) although the difference was not statistically significant. 


\section{Discussion}

We did not find a significant association between thyroid function and vascular parameters in subjects who were similar with respect to age, BMI, smoking, menopausal status, and endothelial function modifiers, but who differed in thyroid function. The exclusion of participants with concomitant endocrinologic, renal, or hepatic diseases allowed us to control our analysis for confounding variables and yielded a homogenous population. In addition, by excluding co-morbid conditions, the mean age was reduced, allowing a smaller sample size for the study (21 subjects in each group). This may be the reason we did not detect a difference between SHT and control subjects in vasodilation parameters.

We examined endothelial function using a simple noninvasive, harmless method that enables accurate and reproducible assessment of the vascular response to flow increase. FMD is currently the main method used to assess endothelial function and is convenient for clinical practice (37).

Lekakis et al. (24) were the first to describe the negative association between borderline and mild hypothyroidism and FMD. In their study, cholesterol did not differ significantly among groups, but tended to be higher in the hypothyroidism and SHT groups and the authors concluded that higher cholesterol levels may be associated with endothelial dysfunction. LDL-C and apo B levels were significant higher in our SHT group, and we did not find altered FMD compared to the euthyroid group.

Cikim et al. (26) compared 25 subclinical hypothyroid patients (mean age: $32.28 \pm 9.67$ years) and 23 euthyroid subjects (mean age: $35.87 \pm 9.67$ years) strictly matched for atherosclerotic risk factors and demonstrated that the subclinical hypothyroid group had significantly lower FMD values $(15.92 \pm 7.92 \%$ for the euthyroid group and $10.68 \pm$ $3.71 \%$ for the SHT group; $P<0.05)$. No significant differences were observed between groups with respect to other vascular parameters, including carotid artery IMT. Since the lipid profile was comparable between groups, the authors suggested that endothelial function could deteriorate prior to the emergence of hypothyroidism-induced metabolic changes. Cholesterol levels were lower in their study than in the present one $(181.04 \pm 36.71 \mathrm{mg} / \mathrm{dL}$ for the euthyroid group and $179.56 \pm 30.21 \mathrm{mg} / \mathrm{dL}$ for the SHT group). We found similar TSH levels $(8.85 \pm 6.86 \mathrm{mIU} / \mathrm{L})$, but thyroid antibody levels were elevated in their SHT patients (mean: $496.71 \pm 677.09 \mathrm{IU} / \mathrm{mL}$ ), reflecting the autoimmune nature of hypothyroidism. Cikim et al. (26) evaluated the association of thyroid autoantibodies and the FMD/IMT ratio and found no significant correlation. We also could not find any significant association between anti-TPO concentrations and FMD or IMT.

The B-mode ultrasound measurement of IMT in the common carotid artery permits easy evaluation of atherosclerosis. Studies evaluating IMT values in hypothyroid and SHT patients showed conflicting results, which varied from low IMT values in subjects with elevated TSH levels (27) to high $(22,23)$, or unchanged levels $(38)$ compared to euthyroid subjects. The results are controversial but there are important differences between studies. Monzani et al. (22) excluded individuals over 55 years of age, and the mean IMT of their SHT patients was significantly higher in the subgroup older than 35 years. Levothyroxine replacement therapy reduced both LDL-C and mean IMT, suggesting that lipid infiltration of the arterial wall may represent the main mechanism underlying the increase in IMT in SHT. We previously reported no significant differences in mean carotid IMT in a group of subclinical hypothyroid patients compared to a euthyroid group, suggesting that mild SHT is not associated with an increase in cardiovascular risk when assessed by carotid IMT (38).

The causative agent of endothelial damage in thyroid dysfunction conditions is unclear, but seems to be associated with decreased endothelial nitric oxide synthesis due to low hormone levels or inflammation induced by thyroid autoantibodies (39).

Based on our data, minimal thyroid dysfunction had no adverse effects on endothelial function in the patients with SHT. Current evidence is insufficient to support the association between minimal thyroid disease and endothelial dysfunction. Larger studies are necessary to identify if there is any beneficial effect of levothyroxine treatment on endothelial function in patients with subclinical hypothyroidism.

\section{References}

1. Ayala A, Wartofsky L. Minimally symptomatic (subclinical) hypothyroidism. Endocrinologist 1997; 7: 44-50.

2. Canaris GJ, Manowitz NR, Mayor G, Ridgway EC. The Colorado thyroid disease prevalence study. Arch Intern Med

2000; 160: 526-534.

3. Cooper DS. Clinical practice. Subclinical hypothyroidism. $N$ Engl J Med 2001; 345: 260-265.

4. Surks MI, Ortiz E, Daniels GH, Sawin CT, Col NF, Cobin 
$\mathrm{RH}$, et al. Subclinical thyroid disease: scientific review and guidelines for diagnosis and management. JAMA 2004; 291: 228-238.

5. McDermott MT, Ridgway EC. Subclinical hypothyroidism is mild thyroid failure and should be treated. J Clin Endocrinol Metab 2001; 86: 4585-4590.

6. Chu JW, Crapo LM. The treatment of subclinical hypothyroidism is seldom necessary. J Clin Endocrinol Metab 2001; 86: 4591-4599.

7. Gharib $H$, Tuttle RM, Baskin HJ, Fish LH, Singer PA, McDermott MT. Subclinical thyroid dysfunction: a joint statement on management from the American Association of Clinical Endocrinologists, the American Thyroid Association, and the Endocrine Society. J Clin Endocrinol Metab 2005; 90: 581-585.

8. Cabral MD, Costa AJL, Santos M, Vaisman M. Lipid profile alterations in subclinical hypothyroidism. Endocrinologist 2004; 14: 121-125.

9. Teixeira PFS, Reis FA, Reuters V, Almeida C, Vaisman M. Hipotireoidismo subclínico e risco cardiovascular. Rev SOCERJ 2004; 17: 50-56.

10. Arem R, Escalante DA, Arem N, Morrisett JD, Patsch W. Effect of L-thyroxine therapy on lipoprotein fractions in overt and subclinical hypothyroidism, with special reference to lipoprotein(a). Metabolism 1995; 44: 1559-1563.

11. Caraccio N, Ferrannini E, Monzani F. Lipoprotein profile in subclinical hypothyroidism: response to levothyroxine replacement, a randomized placebo-controlled study. J Clin Endocrinol Metab 2002; 87: 1533-1538.

12. Danese MD, Ladenson PW, Meinert CL, Powe NR. Clinical review 115: effect of thyroxine therapy on serum lipoproteins in patients with mild thyroid failure: a quantitative review of the literature. J Clin Endocrinol Metab 2000; 85: 2993-3001.

13. Tanis BC, Westendorp GJ, Smelt HM. Effect of thyroid substitution on hypercholesterolaemia in patients with subclinical hypothyroidism: a reanalysis of intervention studies. Clin Endocrinol 1996; 44: 643-649.

14. Teixeira PF, Reuters VS, Ferreira MM, Almeida CP, Reis FA, Melo BA, et al. Treatment of subclinical hypothyroidism reduces atherogenic lipid levels in a placebo-controlled double-blind clinical trial. Horm Metab Res 2008; 40: 50-55.

15. Bastenie PA, Vanhaelst L, Bonnyns M, Neve P, Staquet M. Preclinical hypothyroidism: a risk factor for coronary heartdisease. Lancet 1971; 1: 203-204.

16. Hak AE, Pols HA, Visser TJ, Drexhage HA, Hofman A, Witteman JC. Subclinical hypothyroidism is an independent risk factor for atherosclerosis and myocardial infarction in elderly women: the Rotterdam Study. Ann Intern Med 2000; 132: 270-278.

17. Monzani F, Dardano A, Caraccio N. Does treating subclinical hypothyroidism improve markers of cardiovascular risk? Treat Endocrinol 2006; 5: 65-81.

18. Volzke H, Schwahn C, Wallaschofski H, Dorr M. Review: The association of thyroid dysfunction with all-cause and circulatory mortality: is there a causal relationship? J Clin Endocrinol Metab 2007; 92: 2421-2429.

19. Vane JR, Anggard EE, Botting RM. Regulatory functions of the vascular endothelium. N Engl J Med 1990; 323: 27-36.

20. Healy B. Endothelial cell dysfunction: an emerging endocrinopathy linked to coronary disease. J Am Coll Cardiol
1990; 16: 357-358.

21. Bonetti PO, Lerman LO, Lerman A. Endothelial dysfunction: a marker of atherosclerotic risk. Arterioscler Thromb Vasc Biol 2003; 23: 168-175.

22. Monzani F, Caraccio N, Kozakowa M, Dardano A, Vittone F, Virdis A, et al. Effect of levothyroxine replacement on lipid profile and intima-media thickness in subclinical hypothyroidism: a double-blind, placebo-controlled study. J Clin Endocrinol Metab 2004; 89: 2099-2106.

23. Nagasaki T, Inaba M, Henmi Y, Kumeda Y, Ueda M, Tahara $\mathrm{H}$, et al. Decrease in carotid intima-media thickness in hypothyroid patients after normalization of thyroid function. Clin Endocrinol 2003; 59: 607-612.

24. Lekakis J, Papamichael C, Alevizaki M, Piperingos G, Marafelia P, Mantzos J, et al. Flow-mediated, endotheliumdependent vasodilation is impaired in subjects with hypothyroidism, borderline hypothyroidism, and high-normal serum thyrotropin (TSH) values. Thyroid 1997; 7: 411-414.

25. Papaioannou GI, Lagasse M, Mather JF, Thompson PD. Treating hypothyroidism improves endothelial function. Metabolism 2004; 53: 278-279.

26. Cikim AS, Oflaz H, Ozbey N, Cikim K, Umman S, Meric M, et al. Evaluation of endothelial function in subclinical hypothyroidism and subclinical hyperthyroidism. Thyroid 2004; 14: 605-609.

27. Volzke H, Robinson DM, Schminke U, Ludemann J, Rettig $\mathrm{R}$, Felix SB, et al. Thyroid function and carotid wall thickness. J Clin Endocrinol Metab 2004; 89: 2145-2149.

28. Erbil Y, Ozbey N, Giris M, Salmaslioglu A, Ozarmagan S, Tezelman S. Effects of thyroxine replacement on lipid profile and endothelial function after thyroidectomy. $\mathrm{Br} J$ Surg 2007; 94: 1485-1490.

29. Taddei S, Caraccio N, Virdis A, Dardano A, Versari D, Ghiadoni L, et al. Impaired endothelium-dependent vasodilatation in subclinical hypothyroidism: beneficial effect of levothyroxine therapy. J Clin Endocrinol Metab 2003; 88: 3731-3737.

30. Razvi S, Ingoe L, Keeka G, Oates C, McMillan C, Weaver $\mathrm{JU}$. The beneficial effect of L-thyroxine on cardiovascular risk factors, endothelial function, and quality of life in subclinical hypothyroidism: randomized, crossover trial. J Clin Endocrinol Metab 2007; 92: 1715-1723.

31. National Cholesterol Education Program (USA). Expert panel on detection, evaluation, and treatment of high blood cholesterol in adults. Third report of the National Cholesterol Education Program (NCEP; adult treatment panel III): final report. Bethesda: National Institutes of Health; 2002.

32. Celermajer DS, Sorensen KE, Gooch VM, Spiegelhalter DJ, Miller OI, Sullivan ID, et al. Non-invasive detection of endothelial dysfunction in children and adults at risk of atherosclerosis. Lancet 1992; 340: 1111-1115.

33. Corretti MC, Anderson TJ, Benjamin EJ, Celermajer D, Charbonneau F, Creager MA, et al. Guidelines for the ultrasound assessment of endothelial-dependent flow-mediated vasodilation of the brachial artery: a report of the International Brachial Artery Reactivity Task Force. J Am Coll Cardiol 2002; 39: 257-265.

34. Meirelles CM, Leite SP, Montenegro CA, Gomes PS. Confiabilidade da medida da dilatação fluxo-mediada da artéria braquial pela ultra-sonografia. Arq Bras Cardiol 2007; 89: 160-183 
35. Garrido KU, Leite S, Montenegro C, Koch H, Soares A. Dilatação fluxo-mediada da arteria braquial: estudo da função endotelial em mulheres na menopausa. Rev Bras Ecocardiog 2008; 21: 22-26.

36. Soares DV, Spina LD, de Lima Oliveira Brasil RR, da Silva EM, Lobo PM, Salles E, et al. Carotid artery intima-media thickness and lipid profile in adults with growth hormone deficiency after long-term growth hormone replacement. Metabolism 2005; 54: 321-329.

37. Faulx MD, Wright AT, Hoit BD. Detection of endothelial dysfunction with brachial artery ultrasound scanning. Am
Heart J 2003; 145: 943-951.

38. Almeida CA, Teixeira PF, Soares DV, Cabral MD, Costa $\mathrm{SM}$, Salles EF, et al. Espessura íntima-média carotídea como marcador de risco cardiovascular em pacientes com hipotireoidismo subclínico. Arq Bras Endocrinol Metabol 2007; 51: 472-477.

39. Taddei S, Caraccio N, Virdis A, Dardano A, Versari D, Ghiadoni L, et al. Low-grade systemic inflammation causes endothelial dysfunction in patients with Hashimoto's thyroiditis. J Clin Endocrinol Metab 2006; 91: 5076-5082. 